\section{Analytical Biochemistry}

Vol. 315, Issue 2, 15 April 2003, Pages 152-159

http://dx.doi.org/10.1016/S0003-2697(02)00687-5

(C) 2003 Elsevier Science
Archimer, archive institutionnelle de l'Ifremer http://www.ifremer.fr/docelec/

\title{
Capillary electrophoresis determination of the binding affinity of bioactive sulfated polysaccharides to proteins: study of the binding properties of fucoidan to antithrombin
}

\author{
A. Varenne ${ }^{\star}$, a, P. Gareil ${ }^{\mathrm{a}}$, S. Colliec-Jouault ${ }^{\mathrm{b}}$ and R. Daniel ${ }^{\mathrm{c}}$ \\ a Laboratoire d'Electrochimie et Chimie Analytique, UMR CNRS 7575, ENSCP, 11, Rue Pierre et \\ Marie Curie, 75231, Paris Cedex 05, France \\ ${ }^{\mathrm{b}}$ Laboratoire de Biotechnologie et Molécules Marines IFREMER, DRV/VP/BM, 44311, Nantes Cedex \\ 3, France \\ ${ }^{c}$ Laboratoire de Recherches sur les Macromolécules, UMR CNRS 7540, Université Paris 13, Avenue \\ Jean-Baptiste Clément, 93430, Villetaneuse, France \\ *: Corresponding author :
}

\begin{abstract}
:
The interaction of proteins with polysaccharides represents a major and challenging topic in glycobiology, since such complexes mediate fundamental biological mechanisms. An affinity capillary electrophoresis method has been developed to evidence the complex formation and to determine the binding properties between an anticoagulant polysaccharide of marine origin, fucoidan, and a potential target protein, antithrombin. This method is a variant of zonal electrophoresis in the mobility shift format. A fixed amount of protein was injected into a capillary filled with a background electrolyte containing the polysaccharide in varying concentrations. The effective mobility data of the protein were processed according to classical linearization treatments to obtain the binding constant for the polysaccharide/antithrombin complex. The results indicate that fucoidan binds to antithrombin in a 1:1 stoichiometry and with an affinity depending on the molecular weight of the polysaccharide. For heparin, the binding constant obtained similarly is in accordance with the literature. This is the first report showing the implementation of a capillary electrophoresis method contributing to the mechanistic understanding of the biological activities of fucoidan and providing evidence for the complex formation between fucoidan and the protein inhibitor of the coagulation antithrombin.
\end{abstract}


Studies on the interactions between biomacromolecules are arousing great interest in biology, as many crucial life processes are dependent on their specific molecular recognition. Of a special interest, the carbohydrate-protein interactions are being particularly investigated since it has been recognized that they mediate fundamental biological mechanisms, encompassing growth control, apoptosis, fertilization, cell differentiation, proliferation and morphogenesis as well as physiopathologic disorders like tumoral metastasis, autoimmune diseases, inflammation and host-parasite interactions $(1,2)$. However the mechanisms by which the carbohydrates form a complex with proteins are still poorly understood and now represent a major and challenging topic in glycobiology. The well-known difficulties of analysis of anionic bioactive polysaccharides are important hindrances to a better knowledge of their properties, particularly regarding the strength and the specificity of their interactions with proteins (3). As a consequence the increasing interest in carbohydrate-protein interactions is accompanied by a challenging demand for viable, accurate and high throughput methodologies for their characterization.

Except for few cases, the carbohydrate-protein complexes are often described as resulting from weak non-covalent interactions with $\mathrm{Kd}>1 \mu \mathrm{M}$. As a consequence the analytical method developed for the study of the carbohydrate-protein complexes has to be capable to detect labile complexes. Among the different methods available for studying biomolecular interactions, capillary electrophoresis (CE) offers powerful attributes making this separation method very attractive and well adapted to the study of such non-covalent carbohydrate-protein complexes. CE analysis allows binding assay in solution where the interacting macromolecules are freely mobile at $\mathrm{pH}$ and ionic strength values relevant to the biological conditions. In addition, compared to other methods like gel filtration chromatography, dialysis, classical gel electrophoresis or more recently calorimetry and surface plasmon resonance, it allows on-line detection and requires low amount of sample 
keeping the consumption of carbohydrates and proteins to a minimum. Affinity capillary electrophoresis (ACE) has been introduced for the analysis of receptor-ligand interactions and the determination of binding constants $(4,5,6)$. The basic principle involves the change in charge to mass ratio (inducing a change in electrophoretic mobility) of an analyte through buffer solutions containing dissolved ligands. Scatchard analysis can then be performed to derive the binding constant and interaction stoichiometry $(7,8)$. This approach is then well suited for the study of highly anionic polysaccharides for which a large difference in electrophoretic mobility is expected between the free target protein and the complex. This experimental protocol inherits various advantages of CE such as resolving power, ease of automation, high speed, absence of solid phase and non-denaturating conditions. Given our interest in the study of bioactive anionic polysaccharides, all these attractive performances prompted us to develop a CE method for the quantitative characterization of complex formation between sulfated polysaccharides and target proteins.

Algal fucoidan is a sulfate-based polysaccharide endowed with important properties in several biological mammalian systems (9). Numerous biological activities have been ascribed for this polysaccharide, like anticoagulant and antithrombotic activities as being an activator of both antithrombin and heparin cofactor II $(10,11)$, anti-inflammatory $(12,13)$, antitumoral (14), contraceptive (15) and antiviral (16). Its molecular structure is partially elucidated (17, 18), and therefore the structural basis of its biological properties remains to be established (19). It is generally assumed that these biological properties are related to the capability of fucoidan to achieve specific interactions with target proteins. Concerning the anticoagulant activity, previous studies showed that fucoidan catalysed the activity of the serine proteinase inhibitors antithrombin and heparin cofactor II suggesting a binding of fucoidan to these serpins (20). The complex formed between the anticoagulant sulfated polysaccharide heparin and antithrombin (21) can be considered as the prototype of the carbohydrate-protein complex 
for this study. In this work, we developed and applied an ACE method in order to investigate the capability of fucoidan to make a complex with antithrombin, and to determine its interaction parameters, i.e. the dissociation constant and stoichiometry.

\section{MATERIALS AND METHODS}

Materials. Benzyl alcohol was purchased from Aldrich (Saint Quentin Fallavier, France). The fucoidan used in this study was extracted from the algae Ascophyllum nodosum and purified by size-exclusion chromatography as previously published $(22,23)$. The following fucoidan fractions of different molecular weight were studied i.e. F1 (Mr 2,900), F2 (Mr 5,000) and F3 (Mr 10,000). Heparin (H108, Mr 15,800) from porcine intestinal source was provided as a sodium salt by SANOFI-Recherche (Gentilly, France). Human antithrombin (AT, Mr 58,000) was purchased from BIOGENIC (Maurin, France) and was stocked at $-20^{\circ} \mathrm{C}$ as a $6.25 \mathrm{mg} / \mathrm{mL}$ solution in water. Other chemicals and reagents were obtained from current commercial sources at the highest level of purity available. All buffers and solutions were prepared with ultra pure water produced by an Alpha Q laboratory water purification system (Millipore, Milford, MA).

Capillary electrophoresis. CE experiments were carried out with an $\mathrm{HP}{ }^{3 \mathrm{D}} \mathrm{CE}$ apparatus (Agilent, Waldbronn, Germany). Data were handled by a HPChemstation software. Bare fused silica capillaries, $50 \mu \mathrm{m}$ i.d. (360 $\mu \mathrm{m}$ o.d.) x $35 \mathrm{~cm}$ in length ( $26.5 \mathrm{~cm}$ to detector), were from Beckman (Gagny, France). Samples were introduced in the hydrodynamic mode. The whole injection protocol allowing for both the protein and the neutral marker to be introduced was as follows (see also Table 1) : the neutral marker benzyl alcohol was first injected at a 20 mbar pressure for $2 \mathrm{~s}$, then separation electrolyte (for $2 \mathrm{~s}$ ), antithrombin (for 2 s) and again separation electrolyte (for 5 s) were successively introduced at a 50 mbar 
pressure. Separations were performed under a positive voltage of $20 \mathrm{kV}$ (electric field 570 $\mathrm{V} / \mathrm{cm}$, current intensity $40 \mu \mathrm{A})$. The temperature in the capillary cartridge was set at $25{ }^{\circ} \mathrm{C}$. Analytes were simultaneously monitored by UV absorbance at 200, 214, 230 and $280 \mathrm{~nm}$, using a diode array detector, and the absorbance at $200 \mathrm{~nm}$ was used for calculation. The acquisition rate was 10 points / s.

The separation electrolyte was $20 \mathrm{mM}$ sodium phosphate buffer (50 mM ionic strength, $\mathrm{pH}$ 7.4), containing the sulfated polysaccharide (heparin or fucoidan) at various concentrations ( $2 \times 10^{-8}$ to $2 \times 10^{-3} \mathrm{M}$ ). All electrolytes were filtered through $0.2 \mu \mathrm{m}$ filter units before use. The antithrombin was diluted at $10^{-5} \mathrm{M}$ in the sodium phosphate buffer and injected as described previously. New capillaries were conditioned by successive flushes with $1 \mathrm{M}$ and $0.1 \mathrm{M} \mathrm{NaOH}$ and then with water, for 10,5 and $10 \mathrm{~min}$, respectively. Prior to each sample injection, the capillary was rinsed with the separation electrolyte for $5 \mathrm{~min}$. Capillaries were rinsed with water and dried by air when not in use. The series of experiments for the determination of binding constant consisted in injecting the protein successively in the separation electrolytes containing varying concentrations of polysaccharides. Injections were repeated to check the precision of the data.

Evaluation of the exact length to detector and data treatment. Because of the four successive steps of the injection protocol, the migration length of the analytes did not exactly correspond to the capillary inlet-to-detection window distance, l. The corrected migration lengths $\mathrm{l}_{\text {corr }}^{\mathrm{NM}}$ and $\mathrm{l}_{\text {corr }}^{\mathrm{P}}$ for the neutral marker and the protein respectively were calculated as follows:

$$
\begin{aligned}
& \mathrm{l}_{\text {corr }}^{\mathrm{NM}}=\mathrm{l}-\left(\mathrm{l}_{2}+\mathrm{l}_{3}+\mathrm{l}_{4}\right)-0.5 \mathrm{l}_{1} \\
& \mathrm{l}_{\text {corr }}^{\mathrm{P}}=\mathrm{l}-\mathrm{l}_{4}-0.5 \mathrm{l}_{3}
\end{aligned}
$$


where $l_{1}$ through $l_{4}$ stand for the zone lengths corresponding to the four hydrodynamic injection steps, and numbered in the order of introduction. These lengths were calculated according to equation [3] :

$$
\mathrm{l}_{\mathrm{i}}=\mathrm{d}_{\mathrm{c}}^{2} \cdot \mathrm{P}_{\mathrm{o}} \mathrm{t}_{\mathrm{o}} / 32 \eta \mathrm{L} \quad \mathrm{i}=1 \text { to } 4
$$

where $d_{c}, P_{o}, t_{0}, \eta$ and $L$ stand for the internal capillary diameter, the injection pressure, the injection time, the viscosity of the separation electrolyte and the total length of the capillary, respectively.

Presented in Table 1 are the four successive injection steps, and the corrected migration lengths calculated from the injection parameters. These corrected lengths were considered to calculate the electrophoretic mobility of the analytes. Finally, the apparent $\left(\mathrm{m}_{\mathrm{app}}\right)$, electroosmotic $\left(\mathrm{m}_{\mathrm{eo}}\right)$ and electrophoretic $\left(\mathrm{m}_{\mathrm{ep}}\right)$ mobilities were calculated from the classical equations :

$$
\begin{aligned}
& \mathrm{m}_{\mathrm{eo}}=\mathrm{l}_{\text {corr }}^{\mathrm{NM}} \cdot \mathrm{L} / \mathrm{V} \cdot \mathrm{t}_{\mathrm{NM}} \\
& \mathrm{m}_{\text {app }}=\mathrm{l}_{\text {corr }} \mathrm{P} \cdot \mathrm{L} / \mathrm{V} \cdot \mathrm{t}_{\mathrm{app}} \\
& \mathrm{m}_{\mathrm{ep}}=\mathrm{m}_{\mathrm{app}}-\mathrm{m}_{\mathrm{eo}}
\end{aligned}
$$

where $\mathrm{V}$ is the applied voltage, $\mathrm{t}_{\mathrm{NM}}$ and $\mathrm{t}_{\mathrm{app}}$ denote the experimentally measured migration times of the neutral marker and of the protein, respectively.

\section{RESULTS AND DISCUSSION}

Principle and conditions of the electrophoretic assay. The purpose of this work was to develop an ACE method for the determination of the binding parameters of the sulfated polysaccharides fucoidan and heparin to proteins. Because of the strong anticoagulant property of these polysaccharides, antithrombin (AT) was chosen as the target protein. ACE in its mobility shift format has been widely used to study analyte-ligand interactions. This method is a variant of zonal electrophoresis consisting in the injection of a small amount of 
the analyte of interest while the ligand is present in the running buffer. Provided that the analyte and the ligand have fast association-dissociation kinetics and that the absolute mobilities of the free and bound forms of the analyte are different, then a shift in the position of the analyte peak is expected as the ligand concentration in the running buffer varies. Accordingly, Figure 1 shows a schematic representation of the expected evolution of the electropherograms obtained by this method, for the case of a protein analyte and a ligand. The shift in peak position can then be exploited to determine the strength of the interaction and the number of binding sites.

As the polysaccharides fucoidan and heparin are polydisperse and almost transparent in the whole accessible UV range, ACE was implemented by injecting and detecting the protein AT, the polysaccharides being dissolved in the separation electrolyte. Several wavelengths were first selected to monitor the protein migration (200, 214, 230 and $280 \mathrm{~nm}$ ) and the $200 \mathrm{~nm}$ signal, which presented the best signal to noise ratio was retained to measure the migration time used for subsequent effective mobility calculations.

The analysis was carried out at $\mathrm{pH} 7.4$ near the physiological conditions. At this $\mathrm{pH}$, antithrombin has a negative net charge (pI 5.1), minimizing the adsorption on the negatively charged inner surface of the bare silica capillary, though positive charges are still present on the free amine moieties of the protein. At this $\mathrm{pH}$, both sulfated heparin and fucoidan polyelectrolytes are also negatively charged. The ionic strength was set at $50 \mathrm{mM}$ in order to keep Joule heating within the dissipating capacity of the thermoregulation device. At this ionic strength, analytes are more easily dragged by the cathodic electroosmotic flow existing inside the bare silica capillary, resulting in shorter migration times. Furthermore $\mathrm{pH}=7.4$ and $\mathrm{I}=50 \mathrm{mM}$ are favourable values to the antithrombin-heparin complex formation (24). The experiments were carried out under positive polarity $(20 \mathrm{kV})$, i.e. in a counter electroosmotic migration mode, resulting in an apparent electrophoretic mobility of the protein lower than the 
electroosmotic mobility. A neutral marker (benzyl alcohol) was injected in order to determine the effective mobility of the protein. A sequential injection protocol of the protein and the neutral marker was devised (see Material and Methods) so that the neutral marker, which is injected first, would never be in contact with the protein, thus preventing any risk of deleterious interaction between them. As this resulting injection protocol involved four successive steps, a correction had to be brought to the migration length of AT and benzyl alcohol to avoid any bias in the calculations of the effective mobility (see Eqs 1-6). Furthermore, as the apparent mobilities of the protein and of the complex are higher than the mobility of the polysaccharide, the protein migrates through the capillary in an electrolyte containing the polysaccharide at a concentration that can be considered constant throughout the capillary.

Theoretical determination of the binding constants. The general ACE approach exploits the changes in electrophoretic mobilities of an analyte due to complex formation upon addition of increasing amounts of a ligand to a separation electrolyte. Detailed theoretical treatments and discussions on experimental methods and considerations on the estimation of binding constants can be found in the literature $(25,26)$. Fundamentally, these methods were adapted from similar chromatographic procedures. Basically, a molecular association between an analyte and a ligand can be described by the general rectangular hyperbolic form of a binding isotherm :

$$
y=d x /(f+e x)
$$

The dependent variable, $\mathrm{y}$, is the experimentally measured response of the analyteligand system (in the present case, the effective electrophoretic mobility). The variable $\mathrm{x}$ in equation [7] is the concentration of free ligand, whereas $\mathrm{d}$, e and $\mathrm{f}$ are constants related to the 
properties of the analyte, ligand and complex, and including the binding constant and binding stoichiometry information.

By analogy with the antithrombin-heparin complex which follows a 1:1 stoichiometry (27), a 1:1 complexation equilibrium model was selected $a b$ initio to describe the antithrombin-fucoidan complex. The complexation equilibrium can then be simply schematized as :

\section{Protein $(\mathrm{P})+$ Ligand (L) $\longleftrightarrow$ Complex (C)}

The formation constant relative to this equilibrium is :

$$
K_{f}=\frac{[C]}{[P][L]}
$$

where $[\mathrm{C}],[\mathrm{P}]$ and $[\mathrm{L}]$ are the concentrations of the complex, free protein and free ligand, respectively.

When a free protein is injected in a separation electrolyte containing the ligand, the resulting effective mobility ( $\mu_{\mathrm{p}}{ }^{\text {eff }}$ ) of the protein in equilibrium with the ligand is the average of the absolute mobilities of the free $\left(\mu_{\mathrm{p}}{ }^{0}\right)$ and bound $\left(\mu_{\mathrm{c}}{ }^{0}\right)$ forms of the protein, weighted by the molar fractions :

$$
\mu_{\mathrm{P}}^{\text {eff }}=\frac{[\mathrm{P}]}{[\mathrm{C}]+[\mathrm{P}]} \mu_{\mathrm{P}}^{0}+\frac{[\mathrm{C}]}{[\mathrm{C}]+[\mathrm{P}]} \mu_{\mathrm{c}}^{0}
$$

which, by introducing Eq [8], can be rearranged to yield the binding isotherm equation :

$$
\mu_{\mathrm{p}}^{\text {eff }}=\frac{1}{1+\mathrm{K}_{\mathrm{f}}[\mathrm{L}]} \mu_{\mathrm{p}}^{0}+\frac{\mathrm{K}_{\mathrm{f}}[\mathrm{L}]}{1+\mathrm{K}_{\mathrm{f}}[\mathrm{L}]} \mu_{\mathrm{c}}^{0}
$$

In order to determine the binding constant of the complex, this equation can be transformed into linearized forms, referencing the measured effective mobility $\mu_{\mathrm{p}}{ }^{\text {eff }}$ of the protein to the absolute mobility of the free protein $\mu_{\mathrm{p}}{ }^{0}$ or of the complex $\mu_{\mathrm{c}}{ }^{\mathrm{o}}$, as shown in Table 2 . In addition to the binding constant, it should be noted that the x-reciprocal, y-reciprocal and the double reciprocal methods provide the absolute mobility of the complexed protein $\mu_{\mathrm{c}}{ }^{0}$ (as far 
as $\mu_{\mathrm{p}}{ }^{0}$ is easily measured directly), whereas the linearized isotherm method requires the $\mu_{\mathrm{c}}{ }^{0}$ value to be directly determined experimentally beforehand. A good estimation of the $\mu_{\mathrm{c}}{ }^{\mathrm{o}}$ value can be obtained by measuring the limiting effective mobility of the protein at high polysaccharide concentration.

For the four plotting methods listed in Table 2, significant differences between the mobilities of the free $\left(\mu_{\mathrm{p}}{ }^{\mathrm{o}}\right)$ and complexed protein $\left(\mu_{\mathrm{c}}{ }^{0}\right)$ are required to obtain satisfactory linear correlations. Although the four equations are equivalent in their algebraic form, the experimental precision on the free and dependent variables will affect the correlation differently, according to whether they are included in the numerator or the denominator of the equation. For example, the impact of the precision on variable [L] will alter when the data are transformed to $1 /[\mathrm{L}]$ for plotting in the $\mathrm{x}$-reciprocal and double reciprocal methods. Thus these plots give more statistical weight to the data collected at the lowest concentrations, where the experimental uncertainty is greater $(25,26)$. In this study, we determined the $\mathrm{K}_{\mathrm{f}}$ $\left(1 / K_{d}\right)$ value according to the four methods previously described, so as to evaluate the quality of the experimental measurements.

Finally, the experimental verification of the linearity of these plots will ascertain the concordance with a 1:1 binding system. It is worth remembering that, more generally, when the assumption of a 1:1 complexation is not made, a Scatchard plot, which is equivalent to a x-reciprocal plot, can give an indication of the stoichiometry of the complexation.

Fucoidan and heparin binding to antithrombin. In order to investigate the binding between fucoidan and the target protein antithrombin (AT, Mr 58,000), three fractions of fucoidan differing in their molecular weight (F1, Mr 2,900, F2 Mr 5,000 and F3, Mr 10,000) were studied in this work. For the sake of comparison, a non-fractionated heparin sample (Mr 
15,800) was tested under the same conditions. For each polysaccharide, the concentration added in the running buffer was varied in the range of from $2 \times 10^{-8}$ to $2 \times 10^{-3} \mathrm{M}$.

Figure 2 shows the resulting evolution of the electropherograms of fucoidan F2. A similar electrophoretic behaviour was experienced for the other fucoidan fractions and for heparin. Upon increasing concentration of the polysaccharide, we can note an increase in the migration time of the free and complexed forms of the protein in equilibrium, corresponding to an increase in the charge to mass ratio of the protein. Hence, this evolution indicates the formation of a complex between fucoidan and antithrombin, which was already demonstrated for heparin (27). The effective electrophoretic mobility of the protein $\mu_{\mathrm{p}}{ }^{\text {eff }}$ was systematically calculated for each experiment using Eqs 4 to 6. The four linearization methods described previously were then applied to these sets of mobility data.

Figure 3 shows the treatment of the experimental points for the antithrombin-fucoidan F2 system. The high degree of linear correlation obtained by the four linearization methods testifies to both the precision of the experimental measurements and the pertinence of the 1:1 binding stoichiometry model. Similar conclusions can be drawn for the other two fractions of fucoidan and for heparin. Table 3 summarizes the binding constants (in term of $K_{d}=1 / K_{f}$ ) obtained by each plotting method for each polysaccharide with AT. It should be emphasized that close values of binding constants were obtained for the four methods in all cases, although in some cases one of them yields a result slightly different from the other three ones. As the method yielding this apparently more scattered result was not the same for the different polysaccharides, we deemed it better to express the results as the average of the values provided by the four methods. Thus, the use of the four plotting methods is preferable for the accurate determination of the dissociation constant.

In addition, consistent values were obtained for the absolute mobility of the ATfucoidan complex from the linearized plotting methods (x-reciprocal, y-reciprocal and double 
reciprocal) and from the limiting value of the effective mobility of AT at high fucoidan concentration. This result again demonstrates the overall consistency of the 1:1 binding model and the effectiveness of these four mathematical methods of linearization at providing the binding constant for these AT-polysaccharide complexes. Finally, it can be also noted at this point that the large range of polysaccharide concentrations that were added to the running electrolyte was well adapted to the determination of dissociation constants ranging from a few $10^{-4}$ to $10^{-7} \mathrm{M}$, as these concentrations cover the whole span where different complexation rates occur.

The dissociation constant for the unfractionated heparin H108/AT complex is $\mathrm{K}_{\mathrm{d}}=3.2$ $\mathrm{x} 10^{-7} \mathrm{M}$, which in accordance with the literature values mainly determined by fluorescence spectroscopy (28), ranging from $10^{-7}$ to $10^{-6} \mathrm{M}$. Thus, in addition to the high degree of linearization of the data and the concordance to a 1:1 stoichiometry described in the literature (27), these results support the validity of the present ACE method for similar proteinpolysaccharide complexes.

Many data in literature have pointed out the strong anticoagulant activity of fucoidan, showing that this activity resulted from the rate enhancement of the thrombin inhibition reaction by serpins like antithrombin. Based on these data, it is generally assumed that fucoidan exerts its anticoagulant activity by binding to the serpins (20, 29). However, no fucoidan-antithrombin complex has been evidenced to date. Our results show for the first time that fucoidan, like heparin, is able to bind to AT. The obtained $K_{d}$ values are dependent upon molecular weights of fucoidan, in the same manner as the anticoagulant activity (30). Like heparin, the fucoidan bind to AT in a 1:1 stoichiometry. However the $\mathrm{K}_{\mathrm{d}}$ values indicate that fucoidan does not bind strongly to AT, and therefore its anticoagulant activity could result only partially from the interaction with this serpin. 
The present ACE method in the mobility shift format permits the quantitative evaluation of the antithrombin binding to fucoidans. For the first time, this work brings about thermodynamical evidence of the fucoidan affinity for antithrombin. Thus this methodology allows to characterize the macromolecular polysaccharide / protein complex formation, and is adapted to the identification of proteins interacting with polysaccharides. Concerning the anticoagulant activity, this method will be used to study the interaction of fucoidan with other serpins of the coagulation cascade, particularly with the heparin cofactor II (31). Considering the various biological activities of fucoidan and within the framework of its therapeutical applications, this ACE method is an efficient tool for screening target proteins of fucoidan in other important biological systems. 


\section{REFERENCES}

1. Lee, Y.C., and Lee, R.T. (1995) Carbohydrate-protein Interactions: Basis of Glycobiology. Acc. Chem. Res. 28, 321-327.

2. Williams, S.J., and Davies, G.J. (2001) Protein-carbohydrate interactions: learning lessons from nature. Trends in Biotechnology 19, 356-362.

3. Spillmann, D., and Lindahl, U. (1994) Glycosaminoglycan-protein interactions: a question of specificity. Curr. Opin. Struct. Biol. 4, 677-682.

4. Rippel, G., Corstjens, H., Billiet, H.A.H., and Frank, J. (1997) Affinity capillary electrophoresis. Electrophoresis 18, 2175-2183.

5. Colton, I.J., Carbeck, J.D., Rao, J., and Whitesides, G.M. (1998) Affinity CE : a physicalorganic tool for studying interactions in biomolecular recognition. Electrophoresis 19, 367-382.

6 Heegaard, N.H.H., Nilsson, S., and Guzman, N.A. (1998) Affinity CE : important application areas and some recent developments. J. Chromatogr. B 715, 29-54.

7. Hage, D.S., and Tweed, S.A. (1997) Recent advances in chromatographic and electrophoretic methods for the study of drug protein interactions. J. Chromatogr. A 699, 499-525.

8. Rundlett, K.L., and Armstrong, D.W. (1997) Methods for the estimation of binding constants by capillary electrophoresis. Electrophoresis. 18, 2194-2202.

9. Patankar, M.S., Oehninger, S., Barnett, T., Williams, R.L., and Clark, G.F. (1993) A revised structure for fucoidan may explain some of its biological activities. J. Biol. Chem. 268, 21770-21776.

10. Nagumo, T., and Nishino, T. (1996) Fucan sulfates and their anticoagulant activities. In Polysaccharides in medicinal applications (Dumitriu, S, Ed) pp 545-574. Marcel Dekker, New York, USA. 
11. Millet, J., Colliec-Jouault, S. Mauray, S., Theveniaux, J. Sternberg, C. Boisson-Vidal, C., and Fisher, A.M. (1999) Antithrombotic and anticoagulant activities of a low molecular weight fucoidan by subcutaneous route. Thromb. Haemost. 81, 391-395.

12. Blondin, C., Fisher, E., Boisson-Vidal, C., Kazatchkine, M.D., and Jozefonvicz, J. (1994) Inhibition of complement activation by natural sulphated polysaccharides (fucans) from brown seaweed. Molec. Immunol. 31, 247-253.

13. Angstwurm, K., Weber, J.R., Segert, A., Bürger, W., Weih, M., Freyer, D., Einhäupler, K.M., and Dirnagl, U. (1995) Fucoidin, a polysaccharide inhibiting leukocyte rolling, attenuates inflammatory responses in experimental pneumococcol meningitis in rats. Neurosc. Lett. 191, 1-4.

14. Riou, D., Colliec-Jouault, S., Pinczon du Sel, D., Bosch, S., Siavoshian, S., Le Bert, V., Tomasoni, C., Sinquin, C., Durand, P., and Roussakis, C. (1996) Antitumor and antiproliferative effects of fucan extracted from Ascophyllum nodosum against a nonsmall-cell bronchopulmonary carcinoma line. Anticancer Res. 16, 1213-1218.

15. Mahony, M.C., Oehninger, S., Clark, G.F., Acosta, A.A., and Hodgen, G.D. (1991) Fucoidin inhibits the zona pellucida-induced acrosome reaction in human spermatozoa. Contraception. 44, 657-665.

16. McClure, M.O., Moore, J.P., Blanc, D.F., Scotting, P., Cook, G.M.W., Keynes, R.J., Weber, J.N., Davies, D., and Weiss, R.A. (1992) Investigations into the mechanism by which sulphated polysaccharides inhibit HIV infection in vitro. AIDS Res. Humal Retrovir. 8, 19-26.

17. Daniel, R., Berteau, O., Chevolot, L., Varenne, A., Gareil, P., and Goasdoué, N. (2001) Regioselective desulfation of sulfated L-fucopyranoside by a new sulfoesterase from the marine mollusk Pecten maximus - Application to the structural study of algal fucoidan (Ascophyllum nodosum). Eur. J. Biochem. 268, 5617-5626.15. 
18. Chevolot, L., Mulloy, B., Ratiskol, J., Foucault, A., and Colliec-Jouault, S. (2001) Disaccharide repeat unit is the major structure in fucoidans from two species of brown algae. Carbohydr. Res. 330, 529-535.

19. Mulloy, B., Mourão, P.A.S., and Gray, E. (2000) Structure/function studies of anticoagulant sulfated polysaccharides using NMR. J. Biotech. 77, 123-135.

20. Mauray, S., Sternberg, C., Theveniaux, J., Millet, J., Sinquin, C., Tapon Bretaudiere, J., and Fischer, A M (1995) Venous antithrombotic and anticoagulant activities of a fucoidan fraction. Thromb. Haemostasis 74, 1280-1285.

21. Olson, S. T., Srinivasan, K. R., Bjork, I., and Shore, J. D (1981) Binding of high affinity heparin to antithrombin III. Stopped flow kinetic studies of the binding interaction. J. Biol. Chem. 256, 11073-11079.

22. Mabeau, S., Kloareg, B., and Joseleau, J.P. (1990) Fractionation and analysis of fucans from brown algae. Phytochemistry 29, 2441-2445.

23. Colliec, S., Boisson-Vidal, C., and Jozefonvicz, J. (1994) A low molecular weight fucoidan fraction from the brown seaweed. Pelvetia canaliculata. Phytochemistry 35, 697700.

24. Desai, U.R., Petitou, M., Björk, I., and Olson, S.T. (1998) Mechanism of heparin activation of Antithrombin. J. Biol. Chem. 273, 7478-7487.

25. Connors, K.A. (1987) Binding Constants . The Measurements of Molecular Complex Stability. John Wiley \& Sons, New York, USA

26. Rundlett, K.L., and Armstrong, D.W. (1996) Examination of the origin, variation, and proper use of expressions for the estimation of association constants by CE $J$. Chromatogr. A 721, 173-176.

27. Conrad, H.E. (1998) Heparin-binding proteins. pp 203-238, Academic Press, San Diego, California, USA 
28. Rosenberg, R. D., Oosta, G.M., Jordan, R.E., and Gardner, W.T. (1980) The interaction of heparin with thrombin and antithrombin. Biochem. Biophys. Res. Comm. 96, 1200-1208.

29. Colliec, S., Fischer, A. M., Tapon-Bretaudiere, J., Boisson, C., Durand, P., and Jozefonvicz, J. (1991) Anticoagulant properties of a fucoidan fraction. Thromb Res. 64, 143-154.

30. Nishino, T., Aizu, Y., and Nagumo, T. (1991) The influence of sulfate content and molecular weight of a fucan sulfate from the brown seaweed Ecklonia Kurome on its antithrombin activity. Thromb Res. 64, 723-731.

31. Church, F.C., Meade, J.B., Treanor, R.E., and Whinna, H.C. (1989) Antithrombin activity of fucoidan: the interaction of fucoidan with heparin cofactor II, antithrombin III and thrombin. J. Biol. Chem. 264, 3618-3623 
Table 1 : Corrected migration lengths for the neutral marker, $\mathrm{l}_{\text {corr }}{ }^{\mathrm{NM}}$, and the sample protein, $\mathrm{l}_{\text {corr }}$, as calculated form Eq.1-3 $\left(\mathrm{l}=26.5 \mathrm{~cm}\right.$; dc $\left.=50 \mu \mathrm{m}, \eta=0.88 .10^{-3} \mathrm{~Pa} . \mathrm{s}\right)$

\begin{tabular}{|c|c|c|c|c|c|}
\hline Injection step & $\begin{array}{l}\text { Injected } \\
\text { sample }\end{array}$ & $\begin{array}{c}\text { Injection parameters } \\
\text { (pressure, injection time) }\end{array}$ & $\begin{array}{l}\text { Zone volume } \\
\text { (total volume \%) }\end{array}$ & $\begin{array}{l}\text { Zone length } \\
\quad(\mathrm{cm})\end{array}$ & $\begin{array}{l}\text { Length to detector } \\
\text { (cm) }\end{array}$ \\
\hline 1 & $\begin{array}{l}\text { Benzyl } \\
\text { alcohol }\end{array}$ & $20 \mathrm{mbar}, 2 \mathrm{~s}$ & $\begin{array}{l}1.99 \mathrm{~nL} \\
(0.29 \%)\end{array}$ & $\mathrm{l}_{1}=0.10$ & $\mathrm{l}_{\text {corr }}{ }^{\mathrm{NM}}=25.32$ \\
\hline 2 & $\begin{array}{l}\text { Separation } \\
\text { electrolyte }\end{array}$ & $50 \mathrm{mbar}, 2 \mathrm{~s}$ & $\begin{array}{l}4.98 \mathrm{~nL} \\
(0.72 \%)\end{array}$ & $\mathrm{l}_{2}=0.25$ & \\
\hline 3 & AT & $50 \mathrm{mbar}, 2 \mathrm{~s}$ & $\begin{array}{c}4.98 \mathrm{~nL} \\
(0.72 \%)\end{array}$ & $\mathrm{l}_{3}=0.25$ & $\mathrm{l}_{\text {corr }}^{\mathrm{P}}=25.75$ \\
\hline 4 & $\begin{array}{l}\text { Separation } \\
\text { electrolyte }\end{array}$ & 50 mbar, $5 \mathrm{~s}$ & $\begin{array}{c}12.45 \mathrm{~nL} \\
(1.81 \%)\end{array}$ & $\mathrm{l}_{4}=0.63$ & \\
\hline
\end{tabular}


Table 2:

Linearized forms of the binding isotherm recommended for the determination of binding constants using ACE methods in the mobility shift format.

\begin{tabular}{|c|c|c|c|}
\hline Method name & Plotting method & $\mathrm{K}_{\mathrm{f}}$ determination & $\mu_{\mathrm{c}}{ }^{0}-\mu_{\mathrm{p}}{ }^{0}$ \\
\hline Isotherm & $\frac{\mu_{\mathrm{p}}^{0}-\mu_{\mathrm{p}}^{\text {eff }}}{\mu_{\mathrm{P}}^{\text {eff }}-\mu_{\mathrm{c}}^{0}}=\mathrm{K}_{\mathrm{f}}[\mathrm{L}]=\mathrm{f}([\mathrm{L}])$ & slope & $\begin{array}{l}\text { To be determined by } \\
\text { experiment directly }\end{array}$ \\
\hline X-reciprocal & $\frac{\mu_{\mathrm{p}}^{\text {eff }}-\mu_{\mathrm{p}}^{0}}{[\mathrm{~L}]}=-\mathrm{K}_{\mathrm{f}}\left(\mu_{\mathrm{p}}^{\text {eff }}-\mu_{\mathrm{p}}^{0}\right)+\mathrm{K}_{\mathrm{f}}\left(\mu_{\mathrm{c}}^{0}-\mu_{\mathrm{p}}^{0}\right)=\mathrm{f}\left(\mu_{\mathrm{p}}^{\text {eff }}-\mu_{\mathrm{p}}^{0}\right)$ & - slope & Intercept / slope \\
\hline Y-reciprocal & $\frac{[L]}{\mu_{p}^{\text {eff }}-\mu_{p}^{0}}=-\frac{1}{\mu_{c}^{0}-\mu_{p}^{0}} \times[L]+\frac{1}{K_{f}\left(\mu_{c}^{0}-\mu_{p}^{0}\right)}=f([L])$ & slope / intercept & 1/slope \\
\hline Double reciprocal & $\frac{1}{\mu_{\mathrm{p}}^{\text {eff }}-\mu_{\mathrm{p}}^{0}}=-\frac{1}{\mathrm{~K}_{\mathrm{f}}\left(\mu_{\mathrm{c}}^{0}-\mu_{\mathrm{p}}^{0}\right)} \times \frac{1}{[\mathrm{~L}]}+\frac{1}{\mu_{\mathrm{c}}^{0}-\mu_{\mathrm{p}}^{0}}=\mathrm{f}\left(\frac{1}{[\mathrm{~L}]}\right)$ & intercept / slope & 1/ intercept \\
\hline
\end{tabular}


Table 3 : Dissociation constants $K_{d}$ of human antithrombin complexes with different fucoidan fractions and a commercial reference heparine, as determined by the ACE mobility shift method, using four linearization plotting methods. Experimental conditions as in figure 2. Plotting methods as mentioned in Table 2.

\begin{tabular}{cccccc}
\hline Polysaccharide & $\begin{array}{c}\mathrm{K}_{\mathrm{d}}(\mu \mathrm{M}) \\
\text { isothermal } \\
\text { method }\end{array}$ & $\begin{array}{c}\mathrm{K}_{\mathrm{d}}(\mu \mathrm{M}) \\
\text { X-reciprocal } \\
\text { method }\end{array}$ & $\begin{array}{c}\mathrm{K}_{\mathrm{d}}(\mu \mathrm{M}) \\
\text { Y-reciprocal } \\
\text { method }\end{array}$ & $\begin{array}{c}\mathrm{K}_{\mathrm{d}}(\mu \mathrm{M}) \\
\text { double reciprocal } \\
\text { method }\end{array}$ & $\begin{array}{c}\text { Average value } \\
\text { for } \mathrm{K}_{\mathrm{d}}(\mu \mathrm{M})\end{array}$ \\
\hline $\begin{array}{c}\text { Fucoidan F1 } \\
\text { (Mr 2,900) }\end{array}$ & $2.0 \times 10^{-4}$ & $1.9 \times 10^{-4}$ & $2.4 \times 10^{-4}$ & $2.3 \times 10^{-4}$ & $2.2 \times 10^{-4}$ \\
$\begin{array}{c}\text { Fucoidan F2 } \\
\text { (Mr 5,000) }\end{array}$ & $2.8 \times 10^{-5}$ & $2.9 \times 10^{-5}$ & $5.0 \times 10^{-5}$ & $2.4 \times 10^{-5}$ & $3.3 \times 10^{-5}$ \\
$\begin{array}{c}\text { Fucoidan F3 } \\
\text { (Mr 10,000) }\end{array}$ & $1.2 \times 10^{-5}$ & $2.2 \times 10^{-5}$ & $1.9 \times 10^{-5}$ & $2.0 \times 10^{-5}$ & $1.8 \times 10^{-5}$ \\
$\begin{array}{c}\text { Heparin H108 } \\
\text { (Mr 15,800) }\end{array}$ & $3.2 \times 10^{-7}$ & $5.0 \times 10^{-7}$ & $3.2 \times 10^{-7}$ & $1.6 \times 10^{-7}$ & $3.2 \times 10^{-7}$ \\
\hline
\end{tabular}




\section{CAPTIONS}

Figure 1 : Schematic representation of the protein electropherograms obtained with running buffers containing various concentrations of a ligand, for the determination of their binding parameters. A : no ligand in the running buffer ; B, C : increasing concentration of ligand in the running buffer ; D : ligand concentration for which the protein is totally complexed ; NM : neutral marker transported by the electroosmotic flow.

Figure 2 : Electropherograms showing the mobility shift of antithrombin (AT) as a function of fucoidan F2 concentration in the running buffer. A : $2 \times 10^{-7} \mathrm{M} ; \mathrm{B}: 5 \times 10^{-5} \mathrm{M} ; \mathrm{C}: 10^{-4} \mathrm{M}$ ; D : $1.5 \times 10^{-4} \mathrm{M} ; \mathrm{E}: 2 \times 10^{-3} \mathrm{M}$.

Conditions : bare silica capillary, $50 \mu \mathrm{m}$ i.d. x 35 cm (detection cell, $26.5 \mathrm{~cm}$ ). Running buffer : $20 \mathrm{mM}$ sodium phosphate buffer, $\mathrm{pH} 7.4$ (ionic strength $50 \mathrm{mM}$ ) + fucoidan F2 (various concentrations, A to E). Applied voltage : $20 \mathrm{kV}$ (current intensity: $40 \mu \mathrm{A}$ ). Temperature : $25^{\circ} \mathrm{C}$. Injection protocol : see Table 1 . AT concentration : $2 \times 10^{-5} \mathrm{M}$ in the sodium phosphate buffer, pH 7.4.

Figure 3 : Linearization of the effective mobility variation for antithrombin, in the presence of variable concentrations of fucoidan F2, according to the isotherm (A), x-reciprocal (B), yreciprocal (C), and double reciprocal (D) methods. Concentrations of ligand L (fucoidan F2) in $\mathrm{M}$ and mobilities in $10^{-5} \mathrm{~cm}^{2} \cdot \mathrm{V}^{-1} \cdot \mathrm{s}^{-1}$.

Equations of the least-squares regression straight lines :
$A: y=35222 x-0.0586, R^{2}=0.9947$
$B: y=-34354 x-424863, R^{2}=00.9967$
$C: y=-0.074 x-0.000004, R^{2}=0.949$
$D: y=-0.000002 x-0.0815, R^{2}=0.9989$ 


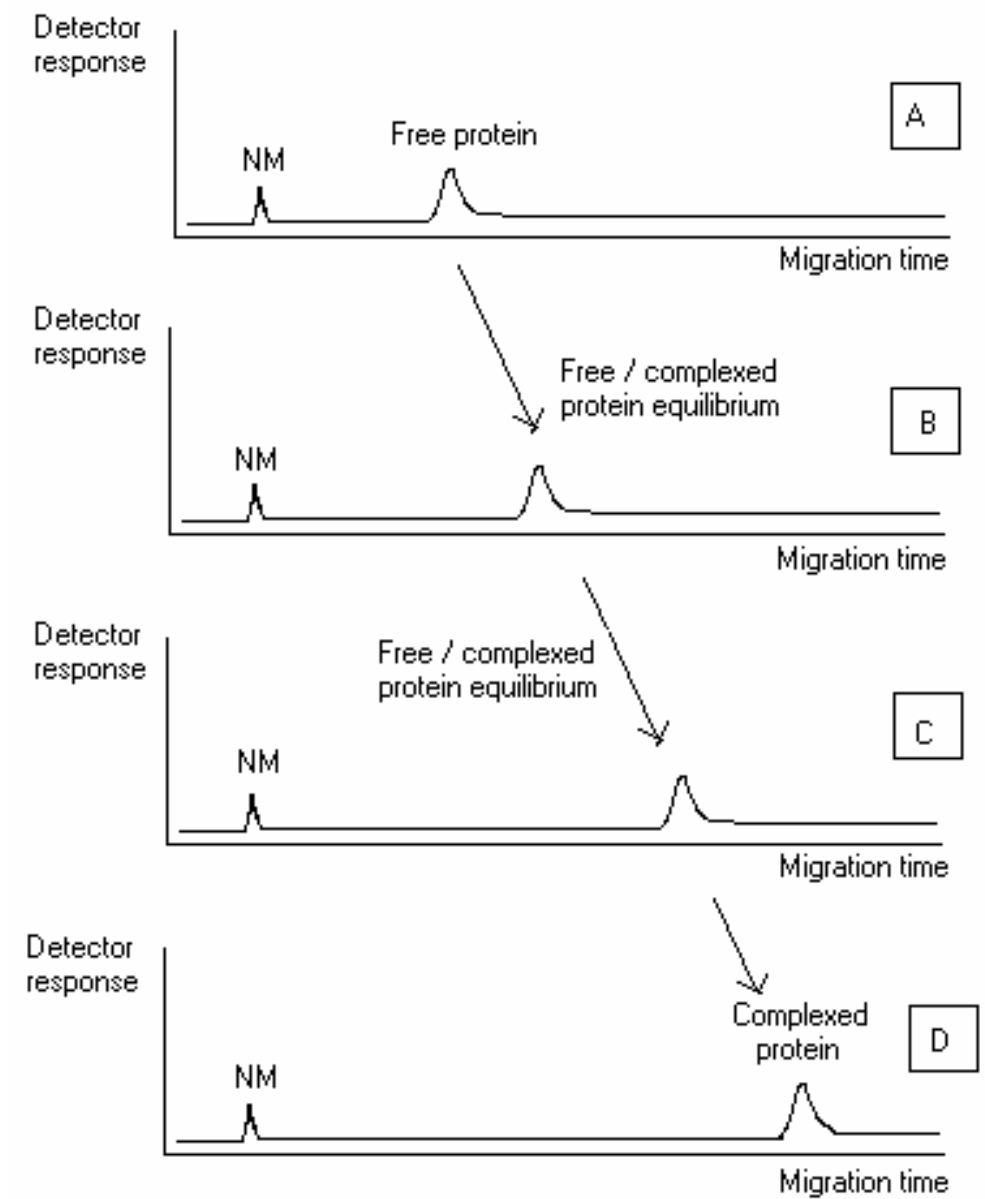



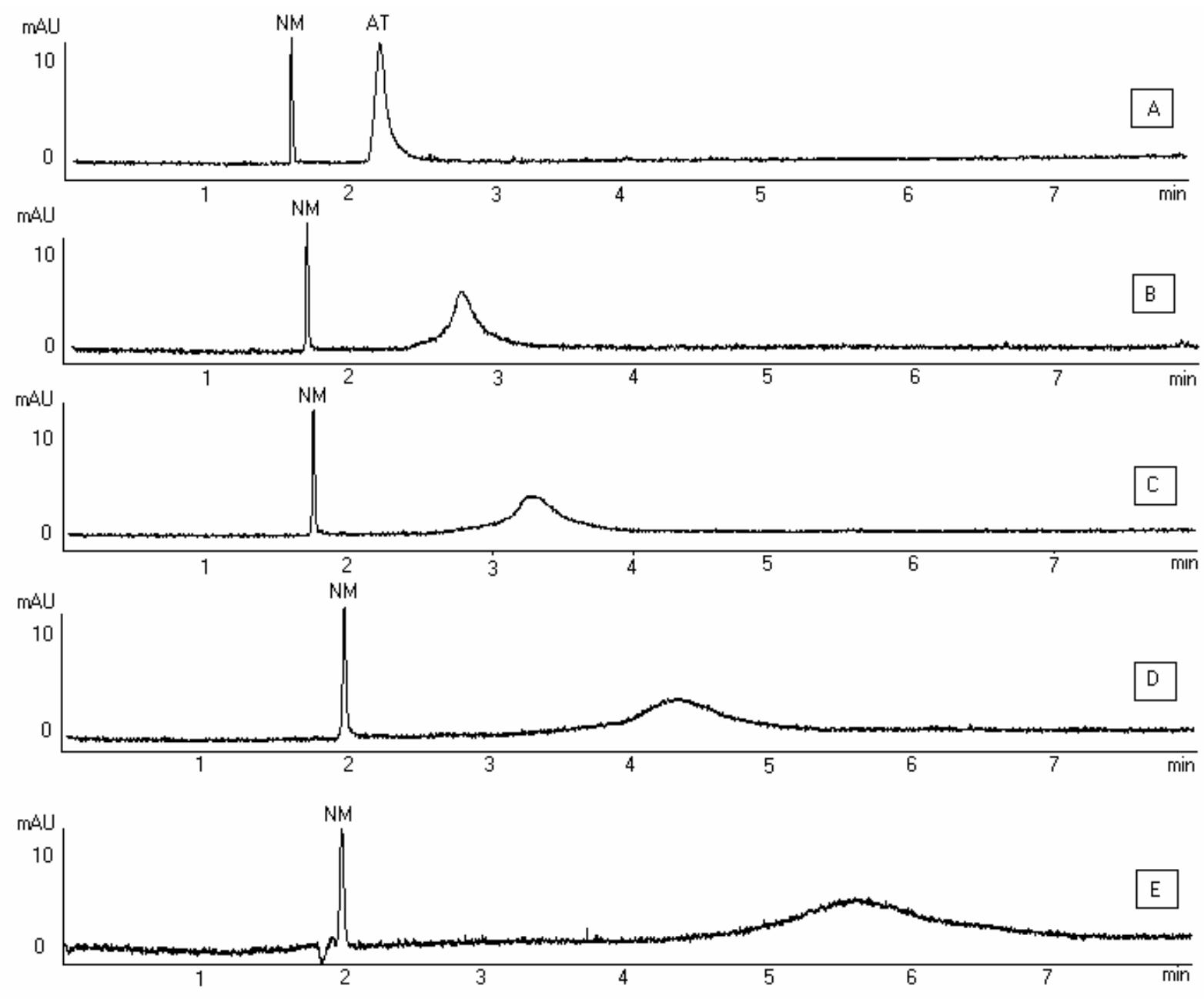

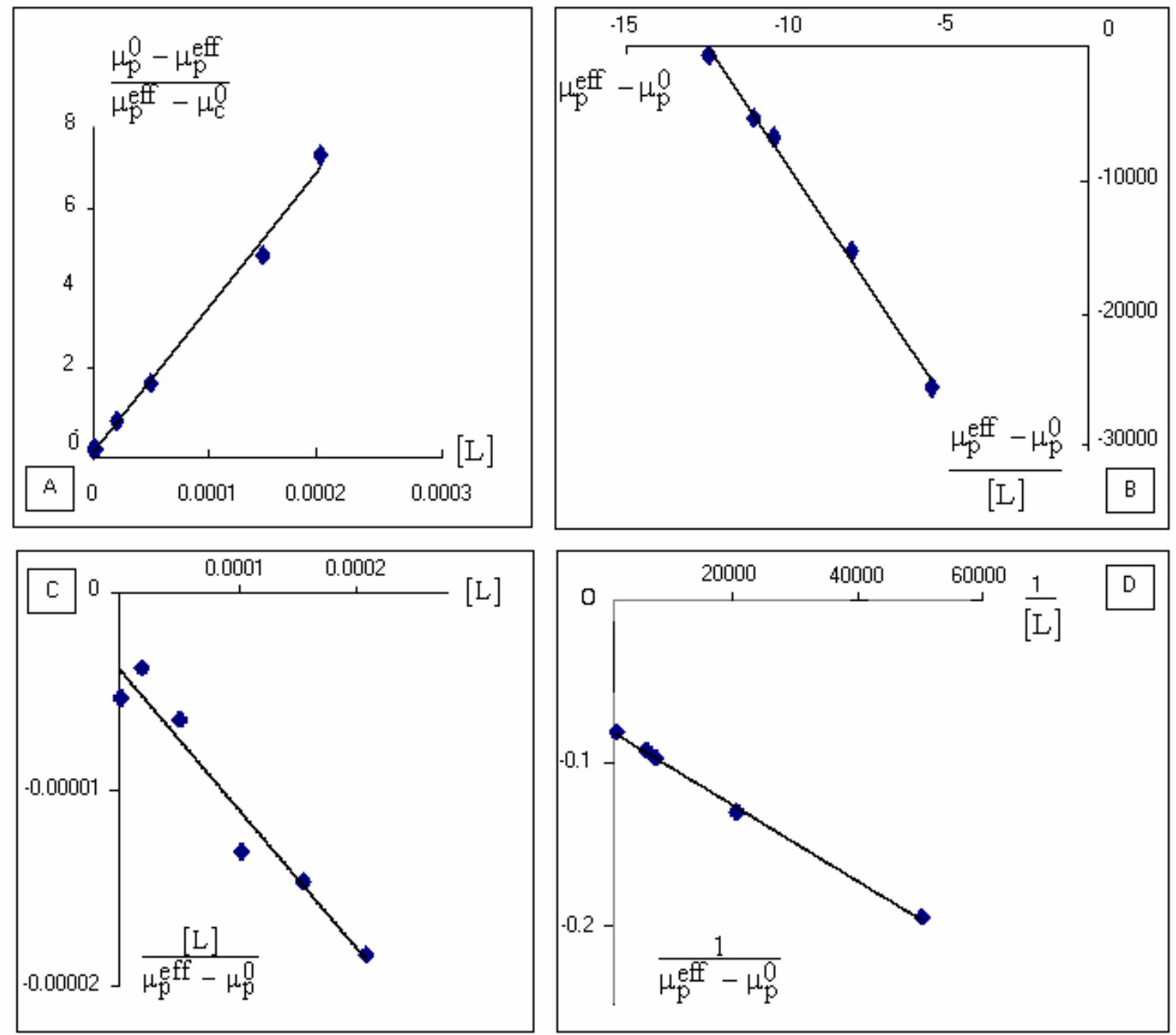